\title{
Analysing customer satisfaction surveys using a fuzzy rule-based decision support system: Enhancing customer relationship management
}

Received (in revised form): 7th March, 2008

\section{Salwa Ammar}

is Professor of Management Science at Le Moyne College. She earned her PhD from the University of Florida. She has extensive experience as a consultant, author, and editor. She has published numerous articles in the field of fuzzy logic and fuzzy-rulebased systems and is a recognised authority in management science education. She is currently the Editor-in Chief of INFORMS Transactions in Education.

\section{David Moore}

is Associate Professor of Marketing and Chair of the Business Administration Department at Le Moyne College. He earned his $\mathrm{PhD}$ in Marketing from the University of Massachusetts. He is a frequent editor and program chair for the Academy of Business Administration.

\section{Ronald Wright}

is Professor of Management Science at Le Moyne College. He earned his PhD from the University of Kentucky. He has over 25 years of experience as a management consultant and has published over 50 papers, most relating to the development and use of decision support systems.

Keywords customer satisfaction, fuzzy rule-based systems, decision support systems, customer relationship management

Abstract Customer satisfaction is an important goal for providers of both services and products, and customer surveys are a commonly used instrument for evaluating that satisfaction. A number of analytical tools are available to assist in the analysis of these surveys. However, under a variety of circumstances, each of these tools has limitations that could seriously restrict their value to marketing managers. This paper describes an innovative approach based on the use of fuzzy-rule-based systems and includes an illustration of the use of the methodology to analyse a customer satisfaction survey conducted by the corporate information division of a major US electric utility.

Journal of Database Marketing \& Customer Strategy Management (2008) 15, 91-105. doi:10.1057/dbm.2008.2; published online 12 May 2008

Ronald Wright Department of Business Administration Le Moyne College, Syracuse, NY 13214, USA Tel: +1 3154454370 ; Fax: +13154454787 e-mail: wright@lemoyne.edu

\section{INTRODUCTION}

Customer satisfaction is commonly recognised as an important goal for both service and production firms. Empirical studies have established the relationship between customer satisfaction, customer loyalty, and long-term profitability. ${ }^{1}$

Consequently, firms devote considerable efforts to ascertaining the extent to which customers are satisfied using tools ranging from focus groups to quantitative customer surveys. $^{2-4}$ Analysts can be concerned with 
identifying an overall measure of satisfaction, but they are equally likely to want to identify the aspects of a product or service that lead to a customer's sense of satisfaction and the relative contribution of each aspect to the overall level of satisfaction. ${ }^{5}$

Many instruments and techniques have been developed to assist in the measurement of both overall and attribute-based satisfaction. Some, such as the critical incidence technique ${ }^{6,7}$ and analysis of complaints and complements ${ }^{8}$ utilise a careful item-by-item assessment and can be based on customer interviews or detailed surveys with open-ended questions. However, when marketing managers are responsible for evaluating customer satisfaction from large and perhaps exhaustive samples, the difficulty of processing and analysing anecdotal results limits the extent to which these methodologies can be incorporated into a user-friendly procedure. ${ }^{9}$ Many other techniques have been developed that are suitable for surveys that incorporate questions utilising a Likert scale to record customer responses. Such surveys provide results that are well suited for a range of statistical measures most often based on some form of weighted average or the use of linear regression models. These surveys typically ask questions about performance on a range of attributes of services or products as well as questions on the importance of the individual attributes. They might also ask customers to express an overall level of satisfaction.

Briefly, the methods frequently used to analyse such surveys include weighted averages of various types, ${ }^{10,11}$ linear regression often with dummy variables, ${ }^{12,13}$ and the importance grid. ${ }^{14}$ All these methods, however, can encounter some form of limitation. Weighted averages focus on customers' implicitly stated reasons for satisfaction and are used to calculate an overall level of satisfaction ${ }^{11}$ or to calculate a level of satisfaction for a process made up of several attributes. ${ }^{15}$ Weighted averages, however, treat each measure of satisfaction as an independent source of information and assume that overall satisfaction is linearly related to the satisfaction level of a single attribute. Such an approach fails to take into account the interaction between various attributes. It can be argued that overall satisfaction is a distinct measurement that is not merely a combination of satisfaction of individual attributes ${ }^{16}$ and that overall satisfaction and attribute satisfaction are separate but related concepts. ${ }^{17}$

Linear regression models have been used to implicitly calculate the importance of individual attributes based on a customer defined level of overall satisfaction. However, the rank order of attribute importance from implicitly derived regression models often differs significantly from the order of importance as explicitly defined by customers. ${ }^{18}$ The importance grid, originally developed by Varva, ${ }^{14}$ is designed to address these differences in explicitly and implicitly derived importance levels. It is used to classify attributes as exciting when the implicit importance is higher than explicit importance, as basic when explicit importance is higher than implicit importance, and as one-dimensional when explicit and implicit importance are similar. Attempts to validate these classifications against similarly designed models, such as penalty-reward contrast analysis, however, show significantly different results from the two methodologies. ${ }^{18}$ In a recent analysis, Busacca and Padula ${ }^{9}$ compared the results from the importance grid to those of a regression model in which dummy variables were used to measure high, low, and moderate performance. Again, the results from the two methods were significantly different. These inconsistencies create concerns for marketing managers who intend to make decisions based on the results of these tools. 
The different results associated with either the linear regression models or linearly calculated weighted averages would naturally arise in situations in which satisfaction responses at the attribute level are in fact nonlinear. Busacca and Padula ${ }^{9}$ state that 'An increasing body of research has been revealing the existence of nonlinear and asymmetric response of satisfaction to attribute-level performance' citing Kano, ${ }^{19}$ Cadotte and Turgeon, ${ }^{8}$ and Johnston ${ }^{20}$ among others. In addition, Hanson ${ }^{10}$ argues that attribute level satisfaction responses are often highly correlated making it difficult to identify the impact of individual factors.

This paper introduces a completely different methodology for evaluating customer satisfaction. The approach does not assume linearity nor does it assume that satisfaction and dissatisfaction are the flip sides of the same coin. The methodology uses an automated and user-friendly system that builds on marketing managers' expertise while enabling them to analyse data from thousands of surveys with as many measurements as can be conveniently collected from customers. The system not only produces an overall measure of customer satisfaction but also has the capability of directly analysing the impact of any individual attribute or groups of attributes. The approach is based on a combination of two well-recognised methodologies, fuzzy set theory and knowledge-based rule systems. The combination is commonly referred to as fuzzy-rule-based systems (FRBS).

Fuzzy set theory and rule-based systems have traditionally been used in scientific and engineering applications ${ }^{21}$ and are at the core of thousands of patents for instruments used to control everything from small appliances to subways and trains. More recently, these systems have been used successfully in performance evaluation. The first implementation ${ }^{22}$ is a system developed to evaluate the financial management of state governments. This success was followed by systems for evaluating the financial management and capital management of large US cities, ${ }^{23,24}$ for producing bond ratings for US cities ${ }^{25}$ and US public airports ${ }^{26}$ and for evaluating the financial health of public schools. ${ }^{27}$ It seems reasonable that tools that have been successfully used in the context of performance evaluation would also be suitable for evaluating customer satisfaction. The next brief section of the paper describes a customer satisfaction example that will provide the context for illustrating the methodology. This will be followed by a section containing a description of an FRBS designed for this specific context as well as a section containing a few illustrative results. The final section presents a rationale for the system's potential to analyse customer satisfaction.

\section{CUSTOMER SATISFACTION APPLICATION}

The Corporate Information Systems (CIS) Division within a major US electric utility company has used internal client satisfaction surveys for many years. These surveys are used to identify an overall level of satisfaction for each client and also to identify customer services that are in need of improvement. The client satisfaction survey is sent to all personnel within the corporation who have used the services of the CIS Division. There is typically a high response rate with data collected from over several hundred company-employed clients. Each survey contains 35 questions distributed over six groups (see Table 1). Individual questions address services within each of five functions, such as 'how satisfied are you with the completeness of the project deliverables?' (as a part of assessment of the Application Development function). For each question, respondents are asked to indicate both a level of satisfaction with the service, and the importance of the service, using a 1-10 Likert scale. Hence the survey 
Table 1: Survey groups

\begin{tabular}{lc}
\hline Function (group) & $\begin{array}{c}\text { Number of } \\
\text { questions }\end{array}$ \\
\hline Application development & 3 \\
Computer operation & 4 \\
Telecommunications & 5 \\
Personal computers and LAN's & 5 \\
Corporate help desk & 3 \\
Overall business conduct & 15 \\
\hline
\end{tabular}

follows the form of many typical customer satisfaction surveys. However, the preferred way to analyse data from a typical customer survey may well vary according to the intended use of the information and the business context.

From the Vice President's perspective, while he certainly wants to identify areas of dissatisfaction, he also believes it is impractical to provide sufficient resources to result in the highest level of satisfaction for all services. Consequently, he calibrated a survey analysis formula that attempts to measure the extent to which the most important services (from a customer's perspective) received the highest satisfaction ratings. Although the satisfaction and importance scores were individually recorded and noted, the main emphasis was placed upon an evaluation of the relationship between the two. The formula included a calculation of the absolute difference between the level of satisfaction and the perceived importance assigned by clients for each question. This calculation attempted to capture the match between the two levels, where an absolute difference of zero is deemed ideal. With that in mind, the general formula:

$$
\text { Rating }=10-3^{*}|S-I|
$$

where $S$ is the satisfaction score and $I$ the importance score, was designed somewhat arbitrarily, although not totally inconsistent with 'standard' grading procedures. The parameters were picked such that a difference of one between the satisfaction and importance score would lead to a rating of seven, which would be considered a satisfactory result. This rating calculation was used for each individual attribute. In addition, the average rating for all attributes within a function (group) was used as an overall rating for the group.

For the most part, this approach produced high and low scores, where appropriate. The rating method, however, produced several obvious anomalies, which, when discovered, rendered the whole process suspect. In some cases, undeservingly high ratings were reported for responses in which the satisfaction and importance scores match but both at a low level. In other cases, managers expressed concerns that the numbers were evaluated out of context. For example, one customer indicated that her satisfaction level was significantly higher than the importance level for 'communication regarding product status'. The rating formula would result in a very low score. However, this same customer also indicated that the timeliness and quality of project deliverables were very important and excellently met? Why should the IS manager be penalised in a case where communication became less important because the timeliness and quality of the work was outstanding?

These concerns about the fairness of the rating led to a request for a review of the analysis methodology. A weighted average index such as the one created by Bhote ${ }^{11}$ was considered, but that index applied no penalty to satisfaction exceeding importance, one of the element the Vice President wanted to take into account. In the next section, we describe the FRBS designed to address these issues. The rule or knowledgebased aspect of the system addresses the different concerns and perspectives defined by the user. The rules also allow evaluations to be made in the varying context of particular questions. The fuzzy set theory aspect of the system allows survey responses that seem to fall into two or more categories to be effectively handled without 
requiring that the response be identified within one category (as would be the case, eg when using dummy variables within linear regression).

\section{A FUZZY-RULE-BASED DECISION SUPPORT MODEL}

For the purpose of illustration we will focus this discussion on one portion of the CIS survey, namely Application Development.

This portion contains three rating questions (three attributes):

Q1: Quality and completeness of project deliverables.

Q2: Timeliness of the project deliverables.

Q3: Communication regarding project status.

\section{Evaluating responses to individual questions}

Each respondent indicates a level of importance and satisfaction for each question, using a scale from 1 to 10 (where 1 is least and 10 is most). For example, a client may assign a response of 9 to importance and a response of 10 to satisfaction for 'the quality and completeness of project deliverables' (Q1). Using the rating formula above, these responses would yield a rating of seven (a satisfactory score). The same rating would result if the respondent's responses for importance and satisfaction were 5 and 6 , respectively. One can certainly make an argument that these two scenarios are not equivalent and that the response with the higher satisfaction and higher level of importance should lead to a higher rating. This simple example makes it clear that the rating must incorporate not only the relationship between the two factors but also their individual values as well. It might also be relevant to consider the relationship in terms of whether satisfaction exceeds or is lower than the importance response, as stated by the client. This suggests that the relationship between importance and satisfaction needs to be represented beyond the absolute difference between the two. The proposed rating system takes into account three factors: the importance response, the satisfaction response, and the actual (not absolute) difference between the two. The system utilises fuzzy set theoretic tools within a rule-based system.

The rule base aspect of the system allows the user to specify evaluation rules such as:

If the importance level is 'high', and the satisfaction level is 'moderate', and the difference between the two is 'negative',

then the rating is 'fair'.

The use of such rules would normally require that a 'high' level of importance be defined perhaps as a response of 8,9 , or 10 . Similarly, a 'moderate' level might be defined as 4, 5, 6, or, 7, and 'low' as 1, 2, or 3 . This categorising of importance into three levels is precisely what takes place in linear regression models in which importance is treated as a dummy variable. ${ }^{9,12,28}$ One considerable disadvantage of such an approach is that there is an abrupt jump from one category to the next. A 7 is 'moderate' but an 8 is 'high'. Hence the difference between a response of 7 and one of 8 is treated identically to the difference between a response of 4 and one of 10 !

Fuzzy set theory, an analytical tool developed to represent imprecision, including the form inherent in linguistic expression, ${ }^{21}$ allows us to describe a gradual shift from one category to another.

Categories can be represented by fuzzy sets defined by a function in $[0,1]$ indicating the level of membership of a given value in the specific category. Categories are expected to overlap, representing the gradual transition (grey areas) between them. 
Definition of the fuzzy sets requires the determination of overlapping ranges for each set and the membership level function. Although the response scale is $1-10$, most responses for importance range from 7 to 10 , and for satisfaction from 5 to 10 . The difference between the two responses tends to range from -4 to +4 . In order to develop a meaningful and manageable rule base, these three factors are assigned three fuzzy categories each. 'Low', 'medium', and 'high' are the categories for the importance and satisfaction levels, and 'negative', 'near zero', and 'positive' for the factor representing the difference between the two (importance-satisfaction). The categories are defined as fuzzy sets over the possible values. Figure 1 illustrates the fuzzy sets selected to interpret the three factors used to evaluate (Q1). For example, if a client gives an importance response of 8 for Q1, the fuzzy sets indicate a 0.47 membership in the 'low' importance category as well as a 0.53 membership in the 'moderate' category. Similarly, a satisfaction response of 9 represents approximately a 0.36 membership in the 'moderate' category and a 0.64 membership in the 'high' category. The difference of importance minus satisfaction has, in this case, a value of -1 . This represents a 0.33 membership in the 'negative' category and a 0.67 membership in the 'near zero' category (see Figure 1).

The fuzzy sets and their transition points may vary from question to question depending on the range of the survey responses.

The fuzzy set representation reflects the imprecision in the score and allows the gradual transition from one category to the next. Now a rule-based system can be designed to evaluate the scores in a manner that is not sensitive to small changes in values, and where multiple assessments can be applicable to any given set of scores.
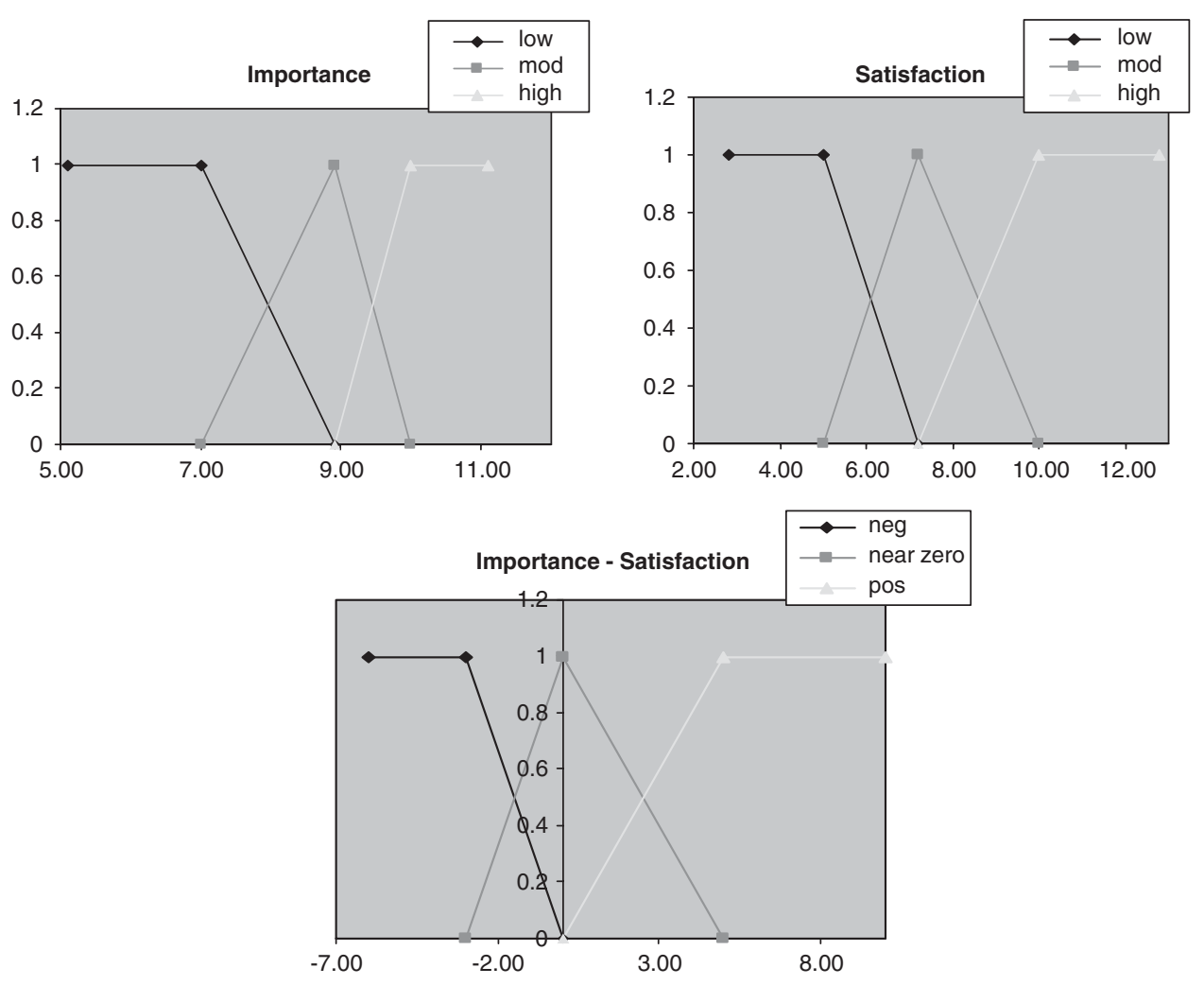

Figure 1: Fuzzy sets for scores of Q1 


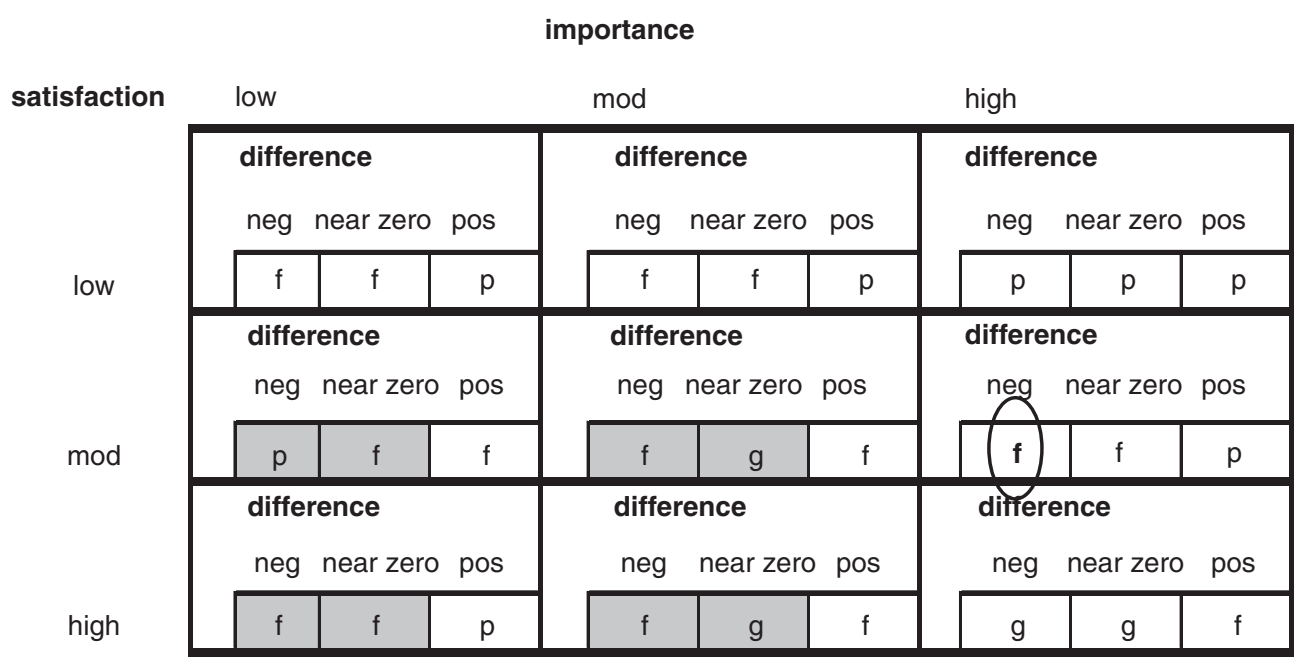

Figure 2: Rule base for Q1

An example of a rule base for Q1 is given in Figure 2. The rule base incorporates the three measures of evaluation and defines a conclusion of 'poor (p)', 'fair (f)', or 'good (g)' for all combinations of the evaluation factors.

For example, the circled cell in Figure 2 can be stated as the following rule:

IF

Importance is 'high'

Satisfaction is 'moderate'

And Difference is 'negative'

THEN

The rating is 'fair'

The rules take into account the interaction of the three factors. For example, if the satisfaction matches the importance but at a low level (northwest corner), the rating would be less than if the match is at the high level (southeast corner).

Since all the responses were evaluated with fuzzy measures, more than one rule comes into play for each response. The shaded cells in Figure 2 represent the multiple rules that would apply for the illustrative response given above, where to some extent the importance was 'low' and 'moderate', the satisfaction was 'moderate' and 'high', and the difference was 'negative' and 'near zero'. The result of each rule is scored using a fuzzy measure following the fuzzy set theoretic extension principle. ${ }^{29}$ For example, consider the single rule (from Figure 2) that resulted in a 'poor' conclusion.

IF fuzzy measure

Importance is low 0.47

Satisfaction is moderate 0.36 And Difference is negative 0.33 THEN

The rating is poor

Since a poor conclusion requires all three conditions, the resulting poor rating can apply only to the extent that all three conditions hold. Hence, following the fuzzy set theoretic extension principle, the poor rating is defined as the minimum of the fuzzy measures for the three conditions.

In this illustration there are two rules that result in a good rating as described below.

IF

Importance is moderate $\quad 0.53$

Satisfaction is moderate $\quad 0.36$

And Difference is near zero 0.67 THEN

The rating is good

0.67 
IF

Importance is moderate

fuzzy measure

Satisfaction is high

0.53

0.64

And Difference is near zero 0.67

THEN

The rating is good

0.53

In this instance we can conclude that the rating is good with a measure of 0.67 or that it is good with a measure of 0.53 . Using the fuzzy set theoretic extension principle, the overall conclusion is the maximum of the two measures.

Consequently, the rating is good with a fuzzy measure of 0.67 .

Finally in this illustration there are five rules that have a result in a fair rating with measures or $0.36,0.33,0.47,0.33$, and 0.33 . The maximum measure of 0.47 defines the fuzzy measure for the fair rating. All together, the rating for this one response is that it is poor with measure 0.33 , fair with measure 0.47 , and good with measure 0.53 . Hence, the output of a fuzzy rule-based system yields a fuzzy conclusion. This application of multiple rules with a fuzzy range of conclusions adds robustness to the results and avoids inconsistencies.

The fuzzy results provide a measurement of the extent to which the customer's response should be evaluated as poor, fair, or good. Although the fuzzy representation contains the complete information from the evaluation process, it is sometimes desirable to combine the fuzzy measures into a single value. Many methods for making this conversion (defuzzifying) are available. This system utilises a centre of gravity calculation. ${ }^{29}$ The detail of the defuzzification process is described in the Appendix. The defuzzified values can be used to provide a ranking for the question ratings. The fuzzy information, however, should also be preserved and reported as it contains all the components of the evaluation.

\section{Evaluating the group/function}

When we consider the Application Development function, each of its three questions can be evaluated individually as described above. The next step in the evaluation process would be to create a rule base that combines the three results into an overall evaluation (see Figure 3). The rule base enables the context of the interaction of the three questions to be incorporated into an evaluation for the whole function (Application Development). For example, the rating on the communicating the project status (Q3) might be less relevant if the timeliness $(\mathrm{Q} 2)$ rating is good.

Using a rule base to evaluate more than four questions at a time becomes particularly cumbersome primarily for the expert user as he or she tries to sort

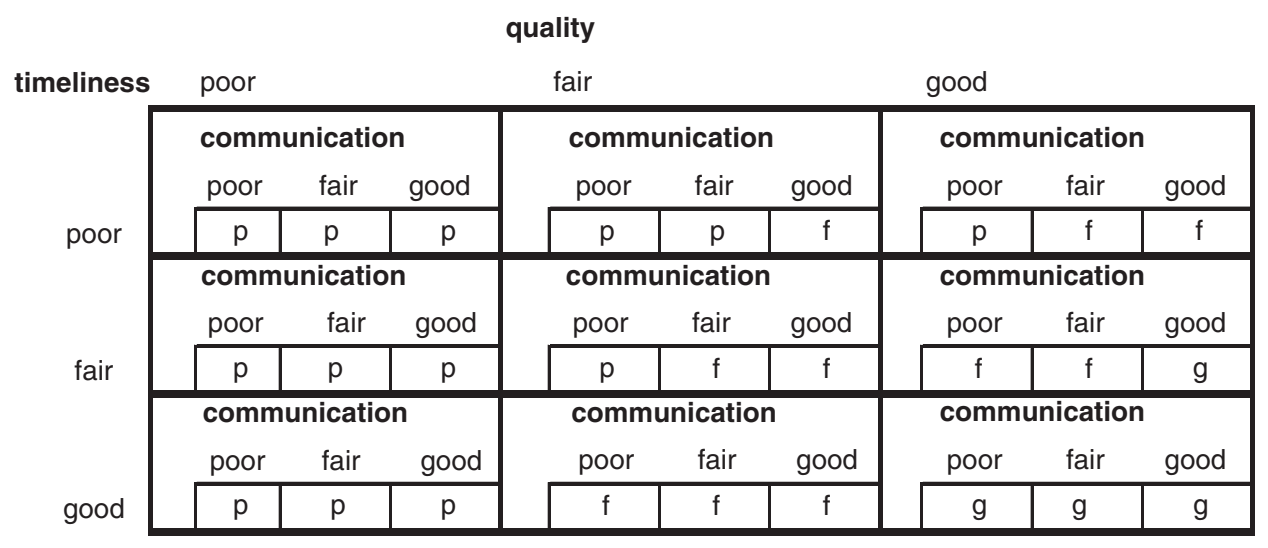

Figure 3: Rule base for Application Development group 
through the relationship between more than four factors. For the functions that used five questions on the survey, questions are first evaluated in smaller groups of two, three, or four and the results of those evaluations are combined using a higher level rule base. For example, for the function dealing with personal computers and LANs, the questions that are relevant to personal computers are evaluated in one rule base and those relating to LANs in a second. In these instances some questions might well appear in both rule bases. The fuzzy output for the two separate rule bases can be evaluated, perhaps along with one or more questions relating to both PCs and LANs, in a higher level rule base that would produce a final fuzzy rating for this function.

This process would be extended to each of the seven functions producing a separate evaluation for each. If desired, the seven individual evaluations could be combined to produce an overall rating for each client. The nature of the systems allows the user to focus on any aspect of the evaluation.

Managers can focus on clients with low levels of overall satisfaction and the system can be used to precisely identify the functions that led to the low rating as well as the reasons why those functions were rated poorly. The level of detail sought remains at the discretion of the system user.

\section{RESULTS}

To illustrate the appropriateness and robustness of the model, this section compares the model results to both the Vice Presidents original calculation and Bhote's ${ }^{11}$ customer satisfaction index. For this illustration, we again focus on the group of questions related to Application Development. The defuzzified scores allow for simple ranking and comparison of the responses while the fuzzy measures provide more information for understanding individual responses.
Table 2: Frequency of defuzzified scores for Q1

\begin{tabular}{lc}
\hline $\begin{array}{l}\text { Defuzzified score ranges } \\
\text { (rounded to integers) }\end{array}$ & Frequency \\
\hline 20 & 13 \\
$17-19$ & 9 \\
$15-16$ & 19 \\
$11-14$ & 16 \\
$9-10$ & 24 \\
$5-8$ & 12 \\
$3-4$ & 12 \\
$0-2$ & 18 \\
\hline
\end{tabular}

The defuzzified results are calculated on a scale of $0-20$. The larger range was selected to avoid confusion with the Likert scale of $1-10$. A score of 0 represents a result that is fully 'poor' while a 20 represents a fully 'good' result. A fuzzy score that is fully 'fair' (with measure 1.0) would receive a 10. Hence any score below 10 would represent a response that is poor to some degree. For the 123 responses to Q1 (quality and completeness of project deliverables), the results are summarised in Table 2 .

The usefulness of these results can in part be investigated by comparing these scores to the scores originally produced by the Vice President of the CIS Division. Figure 4 contains a graph of the relation between the original relationship score and the defuzzified scores for the 123 respondents.

The first observation is that the original calculation allows for negative scores whenever the absolute difference between the satisfaction and importance exceeds three. In extreme cases the original can be as low as -17 . Since an FRBS represents a logical evaluation as opposed to one derived from a simple equation, the FRBS ceases to distinguish among the levels of poor evaluation beyond a certain measure. This is to say that at some point it hardly matters how poor the score is. Consequently, the fuzzy system yields a score of zero for the extreme cases scored by the original relationship at -5 or lower.

Beyond the extremely poor scores, there is a tendency for higher original relationship scores to match with higher defuzzified 


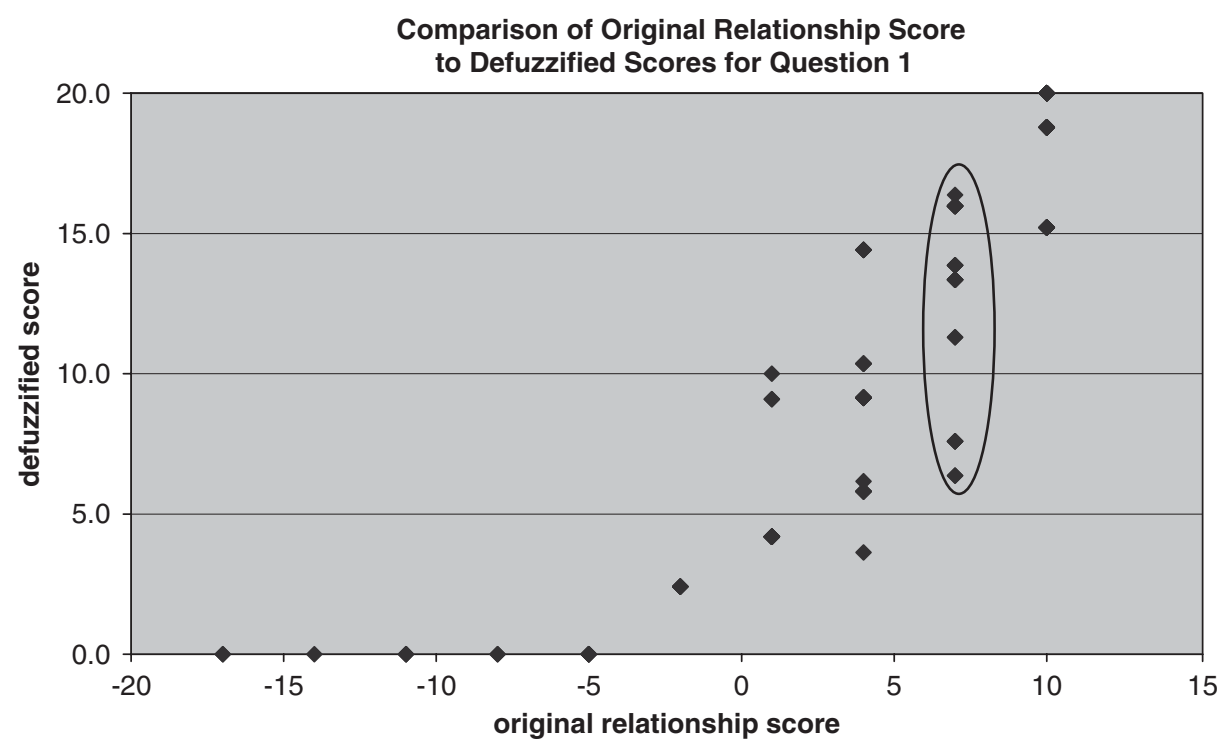

Figure 4: Comparison of original relationship to fuzzy results for question 1

scores. However, there are significant variations that provide insights into the difference between the two approaches. For example, responses that result in a relationship score of seven have defuzzified scores that range from 6.4 to 16.4 (circled points on the graph). A look at the extreme values illustrates the advantages of the fuzzy system. The result that yields a 6.4 was based on an importance response of 5 and a satisfaction response of 6 . The result that yields a 16.4 was the consequence of an importance response of 9 and a satisfaction response of 10 . The rules built into the fuzzy rule-based system judged that a customer who deems a service as very important and has the highest level of satisfaction is a better satisfied customer than one who deems the service as only moderately important with a moderate level of satisfaction. Consequently, the rule-based system allows the same level of relationship to be judged differently, in the context of a customer that more highly valued the service.

To further assess the results for this model, we compare the defuzzified results of the FRBS for the Application
Development Group to the Customer Satisfaction Index (CSI) used by Bhote. ${ }^{11}$ The latter calculates an overall level of satisfaction while taking into account both customer assessed importance and satisfaction. The equation for the index is as follows:

$$
C S I=\frac{\sum_{i=1}^{n} I_{i}-S_{i}}{\sum_{i=1}^{n} I_{i}-R} \times 100 \%
$$

where $n$ is the number of attributes; $I$ the importance score of attribute $i$; $S$ the satisfaction score of attribute $i$; and $R$ the range of scale.

The difference between the CSI results and the FRBS results is illustrated in Figure 5 for the 123 clients. Again there is a general tendency for higher scores in one methodology to be associated with higher scores in the other. But, it is also the case that there are significant deviations. The FRBS produces an overall evaluation that takes into account the context associated with each measurement. For example, one client evaluates Q2 (timeliness) with a 9 for importance and 8 for satisfaction, evaluates 


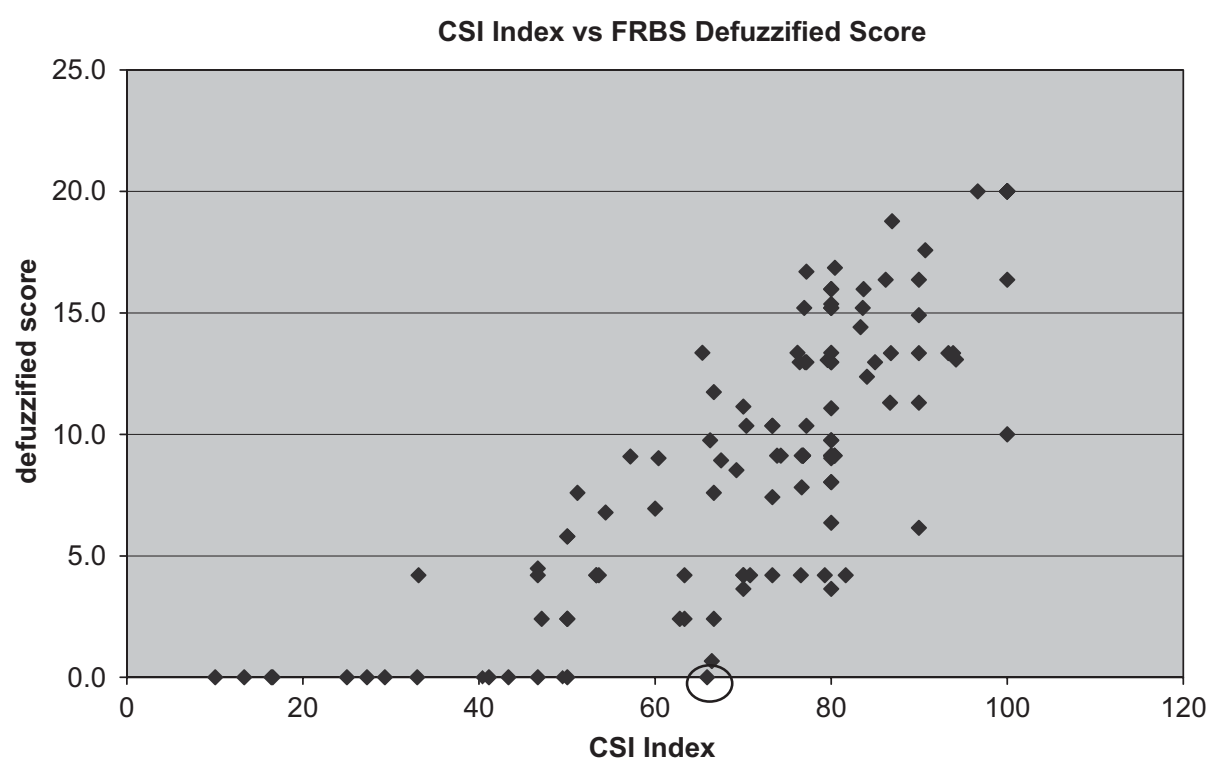

Figure 5: Comparison of CSI to FRBS

Q3 (communication) with an importance of 8 and a satisfaction of 7 . The CSI calculation treats these results as measuring a reasonable level of satisfaction and would score these two attributes at 75 out of 100 . Notably, this client evaluated the "quality and completeness of project deliverables' with an importance level of 10 and a satisfaction level of 5 . Adding the results of this third attribute drops the CSI to 66 , not far from the average of 71 for all 123 clients. For the same client response, the FRBS records a value of 0.0 denoting a fully poor assessment (circled point on the graph). The judgment incorporated into the FRBS indicates that favourable responses for timeliness and communication can in no way compensate for significant dissatisfaction for a product that the client identifies as very important.

For the most part the FRBS scores tend to describe lower levels of overall evaluation than is the case for the CSI. In many instances, this is because the CSI calculation provides no down grading when satisfaction significantly exceeds importance. This is illustrated in the extreme for a client who rated every question with a 10 for satisfaction but a 7 for importance. The CSI rating was a perfect 100, while the FRBS resulted in an evaluation of 'fair' based on a defuzzified score of 10.0 (out of 20). In this context, a highly satisfied internal client who deems your services to be of low importance should not be regarded as an ideal client nor should that response represent an ideal use of scarce resources. This does not necessarily indicate a weakness in the CSI in general, but it is a limitation when the objective of management is to balance the use of resources so that satisfaction in general closely matches level of importance.

In this particular illustration, the nature of the survey questions and the complex objectives of management make the use of a single formula to analyse the results impractical. It is likely that in many other contexts, the type of product or services, the scope of the evaluation, and the nature of the clients could lead to the need for a system that can incorporate customised judgment into the evaluation. 


\section{SYSTEM IMPLEMENTATION}

Implementing the system requires decisions about the definitions of fuzzy sets and the rules that will be used for each measurement. The range of the data frequently defines the fuzzy sets although in some instances a natural interpretation is preferred. Creating the rules is a simpler task than initially imagined by application users. The user of the system can focus on rules that reflect the kind of judgments that would be made in a careful case-by-case evaluation. Once an initial set of rules is created, the user can compare the system results to the results expected for some well-understood cases or scenarios. In every evaluation application to date, experts have modified their preconceived assessment practices based on what they learn from the system. Actual programming of the fuzzy set calculations and the processing of each rule base is done in a spreadsheet context using Visual Basic programming to create a userfriendly environment. ${ }^{22,24}$

\section{CONCLUDING REMARKS}

The customer satisfaction rating system described in this paper could be particularly useful in situations where it is clear that simple linear relationships do not exist, where attributes evaluations are likely to be highly correlated, and where some ability to make judgments in the context of the specific application is required. The system produces significant advantages in situations in which regular survey results are solicited from all customers and where the number of customers is large. The system provides an automated process that will identify customers requiring specific attention. Once identified, the manager can use the system to quickly determine the specific causes for the customer dissatisfaction. ${ }^{27}$ If the data is regularly solicited and quickly processed, problems can be identified and resolved as early as possible and facilitate maintaining positive relations with all customers. Since the system incorporates a high level of judgment, it will not likely raise flags for minor issues, nor miss important considerations that might be masked by calculations designed to work for general customer satisfaction surveys. Also, since the system makes it simple for the user to consider the rationale for all evaluations of interests, it has the benefit of encouraging an ongoing review of the factors the company considers important in assessing customer satisfaction. Beyond a focus on unsatisfied customers, the system could also be used to carefully evaluate the responses of all major customers, again facilitating mutually satisfying relationships with important partners. In addition to a focus on individual customers, the system can be used to provide evaluations of particular functions, services, or products and to identify potential areas of concern within the corporation, areas requiring additional resources, or perhaps major changes.

Since no predefined formulas and no predetermined data formats are used, FRBSs allow management to consider almost any form of input data. Previously designed systems combined Likert-type survey results with financial data. In the context of customer satisfaction evaluations, information such as customer type, size, or history with the corporation might influence how the system rules should be applied.

One of the most important features of this system is the extent to which it is transparent to the manager. In almost every case the manager will have played a role either in creating the original rules or in modifying those rules as the system is used. In a pervious use of this methodology to evaluate the financial health of school districts, early participants (selected by the state department of education) voiced strong opposition to even the creation of the automated system. By the end of its development these same participants were among the strongest supporters. Similarly, the individual managers in the utility CIS 
division were also great supporters of the final system since they had real input into how the surveys would be analysed. They expressed confidence in the reliability of the results and found them useful for providing focus when discussing ways to improve client service.

The proposed system may not be needed for every form of analysis of customer satisfaction. But in complex contexts where basic analysis tools fail to produce the desired results, the robustness, facility of use, and transparency of FRBSs offer a valuable alternative.

\section{References}

1 Anderson, E., Fornal, C. and Lehmann, D. (1994) 'Customer satisfaction, market share, and profitability: Findings from Sweden', Journal of Marketing, Vol. 58, pp. 53-56.

2 Peterson, R. and Wilson, W. (1992) 'Measuring customer satisfaction: Fact and artifact', Journal of the Academy of Marketing Science, Vol. 20, pp. 61-71.

3 Perkins, W. (1993) 'Measuring customer satisfaction', Industrial Marketing Management, Vol. 22, pp. 247-254.

4 Pizam, A. and Ellis, T. (1999) 'Customer satisfaction and its measurement in hospitality enterprises', International Journal of Contemporary Hospitality Management, Vol. 14, pp. 326-339.

5 Johnston, R. and Lyth, D. (1991) 'Service quality: Implementing the integration of customer expectations and operational capability', in: Brown, S.W., Gummesson, E., Edvardsson, B. and Gustavsson, B. (eds.) 'Service quality: Multidisciplinary and multinational perspectives', Lexington Books, Lexington, MA.

6 Flanagan, J. C. (1954) 'The critical incident technique', Psychological Bulletin, Vol. 51, pp. 327-358.

7 Backhaus, K. and Bauer, M. (2000) 'The impact of critical incidents on customer satisfaction in business-to-business relationships', Journal of Businessto-Business Marketing, Vol. 12, pp. 125-143.

8 Cadotte, E. and Turgeon, N. (1988) 'Dissatisfiers and satisfiers: Suggestions from consumer complaints and compliments', Journal of Consumer Satisfaction, Dissatisfaction and Complaining Behavior, Vol. 1, pp. 74-79.

9 Busacca, B. and Padula, G. (2005) 'Understanding the relationship between attribute performance and overall satisfaction', Marketing Intelligence \& Planning, Vol. 23, pp. 543-561.

10 Hanson, R. (1992) 'Determining attribute importance', Quirk's Marketing Research Review, available at http://216.205.123.133/articles/article_ print.asg_articleid $=430$.

11 Bhote, K. R. (1998) 'The customer loyalty audit', Cambridge Strategy Publications, Alexandria, VA.
12 Brandt, R. D. (1987) 'A procedure for identifying value-enhanced service components using customer satisfaction survey data', in: Surprenant, C. (ed.) 'Add value to your service', American Marketing Association, Chicago, IL, pp. 61-65.

13 Anderson, E. W. and Mittal, V. (2000) 'Strengthening the satisfaction-profit chain', Journal of Service Research, Vol. 3, pp. 107-120.

14 Varva, T. G. (1997) 'Improving your measurement of customer satisfaction', ASQ Quality Press, Milwaukee, WI.

15 Anton, J. (1996) 'Customer relationship management: Making hard decisions with soft numbers', PrenticeHall, Upper Saddle River, NJ.

16 Spreng, R., MacKenzie, S. and Olshavsky, R. (1996) 'A reexamination of the determinants of consumer satisfaction', Journal of Marketing, Vol. 60, pp. 15-32.

17 Oliver, R. (1993) 'Cognitive, affective, and attribute bases of the satisfaction response', Journal of Consumer Research, Vol. 9, pp. 19-21.

18 Matzler, K. and Sauerwein, E. (2002) 'The factor structure of customer satisfaction, an empirical test of the importance grid and the penalty-rewardcontrast analysis', International Journal of Service Industry Management, Vol. 13, pp. 314-332.

19 Kano, N. (1984) 'Attractive quality and must-be quality', Hinshitsu — The Journal of the Japanese Society for Quality Control, Vol. 2, pp. 39-48.

20 Johnston, R. (1995) 'The determinants of service quality: Satisfiers and dissatisfiers', International Journal of Service Industry Management, Vol. 6, pp. 53-71.

21 Bezdek, J. C. (1993) 'Fuzzy models — What are they, and why?,' IEEE Transactions on Fuzzy Systems, Vol. 1, pp. 1-5.

22 Ammar, S., Wright, R. and Selden, S. (2000) 'Ranking state financial management: A multilevel fuzzy rulebased system', Decision Sciences, Vol. 31, pp. 449-481.

23 Ammar, S., Duncombe, W., Jump, B. and Wright, R. (2001a) 'Evaluating city financial management using fuzzy rule-based systems', Public Budgeting \& Finance, Vol. 21, pp. 70-90.

24 Ammar, S., Duncombe, W. and Wright, R. (2001b) 'Evaluating capital management, a new approach', Public Budgeting \& Finance, Vol. 21, pp. 47-69.

25 Ammar, S., Duncombe, W., Hou, Y., Jump, B. and Wright, R. (2001c) 'Using fuzzy rule-based systems to evaluate overall financial performance of governments: An enhancement to the bond rating process', Public Budgeting \& Finance, Vol. 21, pp. 91-110.

26 Ammar, S. and Wright, R. (2004) 'A hybrid system for modeling credit ratings for US airports', Proceedings of IEEE International Conference on Fuzzy Systems, Budapest.

27 Ammar, S., Duncombe, W., Jump, B. and Wright, R. (2005) 'Avoiding fiscal stress: The use of expert systems to assess school district financial condition', with Ammar, S., Duncombe, W. and Jump, B., in: Fowler, W.J. (ed.) 'Developments in school finance, 2004: Fiscal proceedings from the annual state data conference of July 2004', U.S. Department of Education, National Center for Education Statistics, 
Washington, D.C. Government Printing Office, pp. 19-37.

28 Mittal, V., Ross, W. and Baldasare, P. (1998) 'The asymmetric impact of negative and positive attribute-level performance on overall satisfaction and repurchase intentions', Journal of Marketing, Vol. 62, pp. 33-47.

29 Dubois, D. and Prade, H. (1988) 'Possibility theory', Plenum Press, New York. NY.

\section{Appendix}

\section{DEFUZZIFICATION}

Determining defuzzified scores involves a process that reverses fuzzification. To defuzzify fuzzy measures of poor, fair, and good requires defining these three traits as fuzzy sets. We use triangular membership functions with poor defined from 0 to 10 , fair from 0 to 20 with a maximum value of 1 at 10 , and good from 10 to 20 , resulting in scores on a scale from 0 to 20 . The defuzzified score involves calculating the centre of gravity for the area under an alpha-cut function defined as follows:

Let $a$ be the fuzzy measure for poor, $b$ the fuzzy measure for fair; $c$ the fuzzy measure for good.
Let $Y_{p}(x)$ be the fuzzy membership function for poor; $Y_{f}(x)$ the fuzzy membership function for fair; $Y_{g}(x)$ the fuzzy membership function for good.

Let $f(x)$ be the alpha-cut function defined as:

For each $x, f(x)=\max \left(\min \left(a, Y_{p}(x)\right), \min \right.$ $\left.\left(b, Y_{f}(x)\right), \min \left(c, Y_{g}(x)\right)\right)$.

Let $z(a, b, c)=$ defuzzified score for given fuzzy measures of poor, fair, and good, where

$$
z(a, b, c)=\frac{\int_{d}^{e} x f(x) \mathrm{d} x}{\int_{d}^{e} f(x) \mathrm{d} x}
$$

where $d$ and $e$ are defined so that $z(1,0,0)=0$ and $z(0,0,1)=20$. Figure A1 contains an illustration of the defuzzification of an evaluation that was poor with a measure of 0.20 , fair with a measure of 0.33 , and good with a measure of 0.67 . The heavy black line represents the alpha-cut function. The defuzzified score is actually the $x$ coordinate of the centre of mass for the grey area. The rectangular

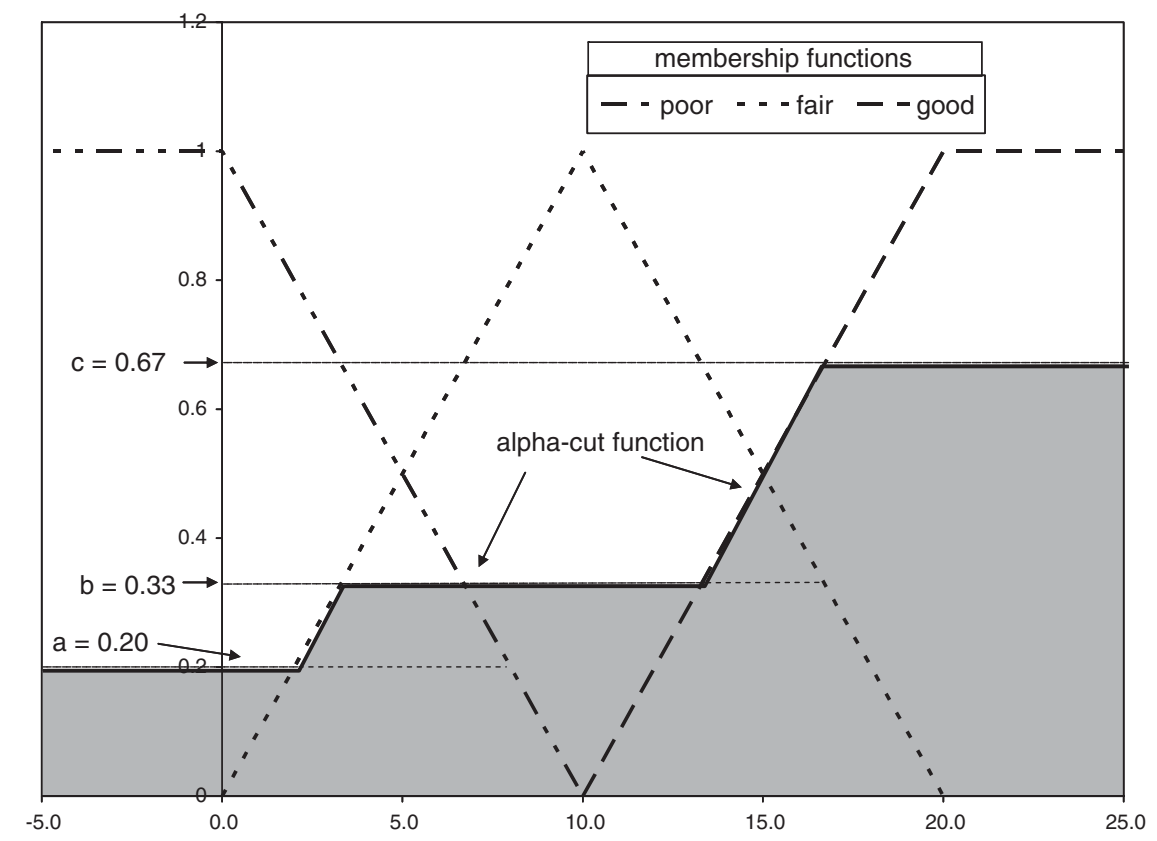

Figure A1: Illustration of alpha-cut function used in defuzzification 
extensions to the membership functions to the left and of 0 and to the right of 20 are counterbalances so that fully poor results receive a score of 0 and fully good results receive a score of 20 . In this instance,

$$
d=-10 \sqrt{3}
$$

and

$$
e=20+10 / \sqrt{3}
$$

Frequently triangular counterbalances are used instead of rectangular counterbalances with $d=-10$ and $e=30$. The calculations in this paper are based on the triangular counterbalances. 